\title{
Analysis of prescriptions for completeness in a tertiary care teaching hospital
}

\author{
Jyothsnya Srinivasa ${ }^{1 *}$, Shubhatara Swamy ${ }^{2}$
}

\author{
${ }^{1}$ Department of Pharmacology, The Oxford Medical College Hospital and Research Centre, Bangalore, Karnataka, \\ India \\ ${ }^{2}$ Department of Pharmacology Vydehi Institute of Medical Sciences and Research Centre, Bangalore, Karnataka, India
}

Received: 24 July 2019

Revised: 26 October 2020

Accepted: 28 October 2020

\section{*Correspondence:}

Dr. Jyothsnya Srinivasa,

Email: jyothsnya@yahoo.co.in

Copyright: (C) the author(s), publisher and licensee Medip Academy. This is an open-access article distributed under the terms of the Creative Commons Attribution Non-Commercial License, which permits unrestricted non-commercial use, distribution, and reproduction in any medium, provided the original work is properly cited.

\begin{abstract}
Background: Prescribing errors are major problems among medication errors. Prescribing errors include mistakes or inaccuracies when choosing and ordering treatments, such as wrong doses or illegible prescriptions. Most of these errors result in no harm or have low to moderate harm however, some result in severe harm or death. There are economic consequences attributed to prescribing errors.

Methods: The aim of the study was to analyse the prescriptions for completeness. The prospective observational study was conducted in outpatient department of different specialities in a tertiary care teaching hospital. Prescriptions with atleast one antibiotic, was collected through duplicate copies from the prescribing doctors. The data obtained from prescriptions were analysed and the conclusions were drawn using descriptive analysis.

Results: A total of 1516 prescriptions with 3957 drugs were prescribed, out of which 1697 were antibiotics. Average number of drugs per prescription was 2.6 and average number of antibiotics per prescription was 1.1. Patient's name, age, and gender were mentioned in $99 \%, 87.8 \%$, and $96 \%$ of prescriptions respectively. Generic drug names were used in $0.7 \%$ of prescriptions. Out of 1681 antibiotics prescribed in 1574 had appropriate dosage form.

Conclusions: The present study highlights the problem of incomplete prescriptions and extensive use of brand names. Intervention strategies focused on education and training, introduction of strict feedback control and monitoring systems are highly effective in reducing prescription errors.
\end{abstract}

Keywords: Prescription errors, Antibiotics, Medication errors

\section{INTRODUCTION}

The United States National coordinating council for medication error reporting and prevention defines a medication error as any preventable event that may cause or lead to inappropriate medication use or patient harm while the medication is in the control of the health care professional, patient, or consumer. Such events may be related to professional practice, health care products, procedures, and systems, including prescribing, order communication, product labelling, packaging, and nomenclature, compounding, dispensing, distribution, administration, education, monitoring, and use. ${ }^{1}$

Prevalence of medication errors widely vary in different parts of the world. In United Kingdom a study found that $12 \%$ of all primary care patients may be affected by a prescribing or monitoring error over the course of a year, 
increasing to $38 \%$ in those 75 years and older and $30 \%$ in patients receiving five or more drugs during a 12 month period. Overall, 5\% of prescriptions had prescribing errors. $^{2}$ A Swedish study found a medication error rate of $42 \%$. However, two-thirds were related to a failure to state the purpose of the treatment on prescriptions and only $1 \%$ of errors resulted in an incorrect dose. ${ }^{3}$ A study from Saudi Arabia reported that under one-fifth of primary care prescriptions contained errors, but only a small minority were considered serious. ${ }^{4}$ Medication errors can give rise to adverse drug events. Study by Gandhi et al reported that $11 \%$ of adverse events were due to medication errors. ${ }^{5}$

Medication errors are one of the most common patient safety issues and prescribing errors are one of the most common types of medication errors. ${ }^{6}$ Prescribing error is defined as a clinically meaningful prescribing error when, as a result of a prescribing decision or prescription writing process, there is an unintentional significant reduction in the probability of treatment being timely and effective or increase in the risk of harm when compared with generally accepted practice. ${ }^{7}$

In India, there are a few published studies pertaining to prescription errors and most of the published studies have addressed the issue in admitted patients. ${ }^{8-10}$ Study by Mohan et al quantifies prescriptions errors as $65 \%$ in outpatient department and among them $22.1 \%$ are type $\mathrm{B}$ errors and $9.5 \%$ are type $\mathrm{C}$ errors. ${ }^{11}$

As suggested by Neville et al prescription errors were stratified according to nuisance they may cause by hampering the dispensing work as follows: type A; errors which are potentially serious to patient, type B; errors causing major nuisance by making a pharmacist to contact the prescriber in order to dispense the medicine, type $\mathrm{C}$; errors causing minor nuisance which can be managed by involving other pharmacist to take a professional decision at dispensary level before dispensing and type D; trivial errors consisting of spelling errors or omissions such as date, age and/or gender of the patient etc. Such errors do not hamper the execution of prescriptions. $^{12}$

Prescription errors of antibiotics results in adverse events as well as play a key role in antibiotic resistance. As antibiotics are commonly prescribed in an outpatient setting, a prospective observational study was planned to assess the prescriptions of outpatient department (OPD) patients for completeness and also to analyse appropriateness of the strength and formulation of the antibiotics prescribed.

\section{METHODS}

Current study was carried out at OPD of general medicine, general surgery, obstetrics and gynaecology
(OBG), orthopaedics, otorhinolaryngology (ENT) and urology at Vydehi institute of medical sciences and research centre, Bangalore, after obtaining approval from the institutional ethics committee during May 2011 to June 2011. Duplicate carbonless copies of the prescriptions with atleast one antibiotics were collected from the doctors at regular intervals. Total of 1516 prescriptions were collected and analysed.

Prescriptions were analysed based on the WHO (world health organization) core drug prescribing indicators (average number of drugs per prescription, average number of antibiotics per prescription and percentage of antibiotics prescribed by generic name). ${ }^{13}$

Prescriptions were analysed for the mentioning of patient's name, age, gender, outpatient number along with the signature of the prescribing physician and date of prescribing. They were also assessed for mentioning dosing schedule, dosage form, dose and route of administration of antibiotic prescribed. Prescriptions from OPD patients were also analysed for appropriateness of the strength and formulation of the antibiotics prescribed.

The data collected from the prescriptions was fed into Microsoft excel sheet to create a data base file. To analyse the antibiotics and adjuvants prescribed, each drug was assigned a code. The master chart was obtained and analysed using descriptive statistics. Results on categorical measurements are presented in number and percentage.

\section{RESULTS}

A total of 1516 prescriptions from outpatient department which met the inclusion and exclusion criteria were analyzed. 3957 drugs were prescribed, out of which 1697 were antibiotics. Average number of drugs per prescription is 2.6 and average number of antibiotics per prescription is 1.1. In department of ENT more than one antibiotic was prescribed in $30 \%$ of prescriptions (Table 1).

Hospital name and address was printed on all prescriptions. The patient's name, age, and gender were present on $99 \%, 87.8 \%$, and $96 \%$ respectively. Outpatient number was mentioned in $81.7 \%$ of prescriptions. None of prescription mentioned the patient's address. $98.1 \%$ of the prescriptions were signed by the prescribing physician. Date of writing prescribing was mentioned in 92.3\% of prescriptions. Analysis of prescriptions in each department reveals that mentioning of gender and age of the patient along with date of prescribing was least in department of general medicine (Table 2). Department of urology followed by department of general surgery have prescriptions with least outpatient number mentioned in them. Outpatient number and age of the patient were least mentioned variables among all the departments analysed. 
Table 1: Distribution of the number of antibiotics prescribed per prescription.

\begin{tabular}{|lllllllll|}
\hline $\begin{array}{l}\text { No of } \\
\text { antibiotics }\end{array}$ & $\begin{array}{l}\text { ENT } \\
(\mathbf{n}=\mathbf{6 0 6})\end{array}$ & $\begin{array}{l}\text { Medicine } \\
(\mathbf{n}=\mathbf{4 4 2})\end{array}$ & $\begin{array}{l}\text { Urology } \\
(\mathbf{n}=\mathbf{1 3 7})\end{array}$ & $\begin{array}{l}\text { Surgery } \\
(\mathbf{n}=\mathbf{1 1 5})\end{array}$ & $\begin{array}{l}\text { OBG } \\
(\mathbf{n}=\mathbf{1 2 5})\end{array}$ & $\begin{array}{l}\text { Orthopedics } \\
(\mathbf{n}=\mathbf{9 1})\end{array}$ & $\begin{array}{l}\text { Total } \\
(\mathbf{n}=\mathbf{1 6 9 7})\end{array}$ & $\begin{array}{l}\text { Total } \\
(\mathbf{\%})\end{array}$ \\
\hline $\mathbf{1}$ & 461 & 431 & 121 & 113 & 122 & 91 & 1339 & 88.3 \\
\hline $\mathbf{2}$ & 143 & 11 & 16 & 2 & 3 & 0 & 175 & 11.5 \\
\hline $\mathbf{3}$ & 2 & 0 & 0 & 0 & 0 & 0 & 2 & 0.1 \\
\hline
\end{tabular}

Table 2: Distribution of prescriptions with parts of prescription mentioned.

\begin{tabular}{|lllllllll|}
\hline $\begin{array}{l}\text { Parts of the } \\
\text { prescription }\end{array}$ & $\begin{array}{l}\text { ENT } \\
(\mathbf{n}=\mathbf{6 0 6})\end{array}$ & $\begin{array}{l}\text { Medicine } \\
(\mathbf{n}=\mathbf{4 4 2})\end{array}$ & $\begin{array}{l}\text { Urology } \\
(\mathbf{n}=\mathbf{1 3 7})\end{array}$ & $\begin{array}{l}\text { Surgery } \\
(\mathbf{n = 1 1 5})\end{array}$ & $\begin{array}{l}\text { OBG } \\
(\mathbf{n = 1 2 5})\end{array}$ & $\begin{array}{l}\text { Orthopedics } \\
(\mathbf{n}=\mathbf{9 1})\end{array}$ & $\begin{array}{l}\text { Total } \\
(\mathbf{n = 1 5 1 6})\end{array}$ & $\begin{array}{l}\text { Total } \\
(\%)\end{array}$ \\
\hline Name & 601 & 437 & 136 & 113 & 125 & 91 & 1503 & 99 \\
\hline Age & 588 & 325 & 118 & 105 & 115 & 81 & 1332 & 87.8 \\
\hline Gender & 591 & 375 & 136 & 111 & 124 & 89 & 1457 & 96 \\
\hline $\begin{array}{l}\text { Outpatient } \\
\text { number }\end{array}$ & 568 & 331 & 84 & 82 & 92 & 83 & 1240 & 81.7 \\
\hline Signature & 597 & 431 & 137 & 113 & 121 & 89 & 1488 & 98.1 \\
\hline Date & 566 & 401 & 128 & 105 & 119 & 81 & 1400 & 92.3 \\
\hline
\end{tabular}

Table 3: Details of appropriate dosage formulation and strength of the antibiotics prescribed.

\begin{tabular}{|lllllllll|}
\hline Departments & $\begin{array}{l}\text { ENT } \\
(\%)\end{array}$ & $\begin{array}{l}\text { Medicine } \\
(\%)\end{array}$ & $\begin{array}{l}\text { Urology } \\
(\%)\end{array}$ & $\begin{array}{l}\text { Surgery } \\
(\%)\end{array}$ & $\begin{array}{l}\text { OBG } \\
(\%)\end{array}$ & $\begin{array}{l}\text { Orthopedics } \\
(\%)\end{array}$ & $\begin{array}{l}\text { Total } \\
(\mathbf{1 6 9 7})\end{array}$ & $\begin{array}{l}\text { Total } \\
(\%)\end{array}$ \\
\hline $\begin{array}{l}\text { Appropriate } \\
\text { formulation }\end{array}$ & 98.7 & 88.6 & 86.3 & 92.4 & 90.5 & 94.3 & 1574 & 93.6 \\
\hline $\begin{array}{l}\text { Appropriate } \\
\text { strength }\end{array}$ & 98.7 & 97.9 & 99.2 & 98 & 100 & 97.3 & 1417 & 98.5 \\
\hline
\end{tabular}

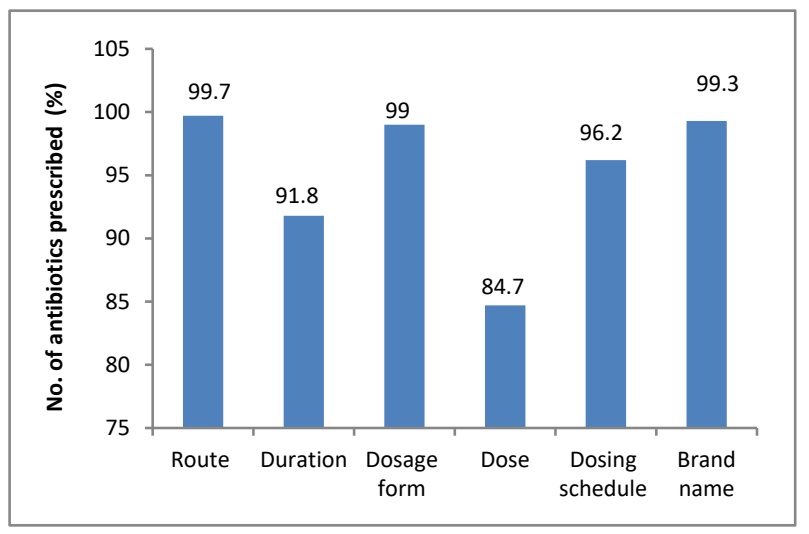

Figure 1: Details of antibiotics mentioned in the prescriptions.

\section{Details of antibiotics prescribed}

Generic drug names were used in $0.7 \%$ prescriptions. $99.3 \%$ of the prescribed drugs were by brand name. Dose and the dosing schedule of antibiotic were mentioned in $84.7 \%$ and $96.2 \%$ of prescriptions respectively. Dosage formulation was mentioned for $99 \%$ while route of administration was mentioned for $99.7 \%$ of antibiotics prescribed. Duration of antibiotic use was mentioned in $91.8 \%$. Instructions to patient were included in about onethird of prescriptions. Diagnosis was mentioned in $10.3 \%$ of prescriptions (Figure 1). Out of 1697 antibiotics prescribed, only 1681 had dose formulation mentioned. Among them 1574 had appropriate dosage formulation, accounting for $93.6 \%$ of the prescriptions. Inappropriate antibiotic dosage formulations were mostly seen in the departments of urology (13.6\%), general medicine $(11.3 \%)$ and OBG (10.4\%). Among the 1438 antibiotics were dose was mentioned, 1417 (98.5\%) had appropriate strength (Table 3). Most of the prescription errors belonged to type $\mathrm{C}$ and type $\mathrm{D}$.

\section{DISCUSSION}

Prescribing errors are the largest source of medication errors. Most people taking medications will benefit from it, but there is always the potential for errors which may cause harm. In a study by Gandhi et al 940 prescriptions were audited and the prescribing error rate was 7.6 per 100 prescriptions. ${ }^{5}$ In study by Mohan et al an error rate of $65 \%$ was observed, with most of the errors as trivial belonging to type D. ${ }^{11}$ In present study, omission of diagnosis, details of the patient (name, age, gender), outpatient number, date of prescribing and signature of the prescribing physician were the major contributor for prescription errors. These contribute type D errors. ${ }^{11,12}$

Being trivial errors they are unlikely to hamper dispensing of the correct drug, however mentioning them, shall help the pharmacist to correlate and interpret the 
correct drug, formulation and dose, especially among the handwritten prescriptions. ${ }^{13}$

Use of brand names in the current study was very high similar to the study by Shanmugapriya et al. ${ }^{14}$ Extensive use of brand names by the prescribing physician, can contribute to prescription errors. In our tertiary care setting where a single pharmacy dispenses drug of various specialties, errors can be common. Alflox (norfloxacin) and alfox (oxcarbazepine) are sound alike drugs, which when wrongly dispensed causes a major effect on the therapeutic success. Contributing to this confusion are illegible handwriting, incomplete knowledge of drug names, similar packaging or labelling, similar clinical use, similar strengths, dosage forms, frequency of administration and the failure of manufacturers and regulatory authorities to recognize the potential for error for drug names, prior to approving new product names. ${ }^{15}$ Hence prescribing drugs by generic names helps to maintain uniformity, clarity, ease of understanding, better dispensing and reduce the cost of medical care. Type B prescription errors are seen with extensive use of brand names. ${ }^{11,12}$

Strength of the antibiotic was not mentioned in $15 \%$ of the prescriptions. Among the strength of the antibiotic mentioned, $1.5 \%$ were inappropriate. Such errors can lead to difficulty in dispensing medications at adequate dose leading to medication errors. These also contribute to type $\mathrm{B}$ errors. ${ }^{12}$

Omission of dosing schedule/dosing instruction were found in $3.8 \%$ prescriptions leading to type B errors. ${ }^{12}$ Dose and dosing schedule is important to achieve therapeutic concentration of the drug, thus leading to therapeutic failure. Dosage formulations of the antibiotics were mentioned in most of the prescriptions but $6 \%$ of the dosage forms prescribed were inappropriate. Omission of duration of treatment and route of administration of the prescribing antibiotic contributes to drug resistance, adverse drug events and therapeutic failure.

Average number of antibiotics prescribed per prescription was 1.1 including the topical antibiotics which is lower than in the study done by Suman et al conducted in ENT department where average number of antibiotics prescribed was $1.69 .{ }^{16}$ In the present study, the average number of drugs per encounter was 2.6 , which is higher than the WHO recommendation of less than 2 drugs per encounter, indicating a trend of polypharmacy. ${ }^{13}$ The reasons that could be attributed to this are, the change in the epidemiological trend of rampantly increased prevalence of non-communicable diseases such as diabetes mellitus, hypertension, dyslipidemia, and coronary artery disease which are often coexistent. These contribute to the need for treating multiple disease entities in the same patient simultaneously.
The common factors that may influence medication errors were mistakes due to inadequate knowledge of the drug or the patient, memory lapses, lack of training or experience, fatigue, stress, high workload, insufficient resources, lack of standardized protocols and inadequate communication between healthcare professionals. As prescribing errors make up a significant proportion of all errors in healthcare, further involvement and work in this field has the potential to significantly improve patient safety. ${ }^{17}$

Prescribing errors are relatively common but preventable events. There are various methods to reduce prescription errors. One to one education, educational outreach visit, audit and feedback were the most effective methods to improve prescribing practices. ${ }^{18}$ Academic detailing, group discussion, interventional strategies and support tools also aid in reducing errors, especially among the junior staff. Structured assessment like objective structured clinical examination (OSCE) can be used to improve awareness about medication errors among the medical students. Monitoring and reporting itself aids in reducing errors. ${ }^{19}$ Other health care professionals like nurses, pharmacist can be included for multifaceted hospital interventions, thus aiming at reducing the errors.

Tools like E-prescribing, decision support, alert systems and personal digital assistant (PDA) can be utilized even in primary care setting. Workflow redesigning, decision support tools, alert system and standardised medication charts are used to reduce human factors resulting in errors. Combination of different tools, educational interventions based on the feasibility have provided reduction in errors than by following a single method. ${ }^{19}$ In our country, evolving and applying such technology across a large number of hospitals and training of manpower remain major impediments in such an endeavour.

Analysis in specific specialties can be subsequently taken up with the inclusion of treating physicians for analysing of the prescriptions. Diagnosis, choice of drug based on clinician preference, for therapeutic or prophylactic use, pathophysiological state of the patient could help to further determine appropriate dose, duration, dosing schedule and route of drug administration aiding to identify and reduce medication errors.

\section{CONCLUSION}

Primary care services are at the heart of health care services in any country. Improving safety in primary care is essential when striving to ensure universal health coverage and the sustainability of health care. Medication errors have a negative impact on patients' health and therefore should be minimized. Understanding the magnitude and addressing issues of prescription errors is essential to improve patient safety in health care. Interventions to prevent prescription errors need to be implemented. Setting up local priorities, measuring and 
monitoring, use of electronic tools and strengthening workforce capacity and capability are few evidence based interventions, which can help to reduce prescription errors.

\section{ACKNOWLEDGEMENTS}

Authors would like to thank Dr. Manjula Shetty and Dr. Kevin Manohar Salis, for their support during study.

Funding: No funding sources

Conflict of interest: None declared

Ethical approval: The study was approved by the Institutional Ethics Committee

\section{REFERENCES}

1. National coordinating council for medication error reporting and prevention; 2015. Available at: http://www.nccmerp.org/about-medication-errors. Accessed on 9 July 2019.

2. Avery AA, Barber N, Ghaleb M, Dean Franklin B, Armstrong $\mathrm{S}$, Crowe $\mathrm{S}$, et al. Investigating the prevalence and causes of prescribing errors in general practice: the practice study. General Medical Council. Available at: https://www.gmc-uk.org/ about/what-we-do-and-why/data-and-research/ research-and-insight-archive/investigating-theprevalence-and-causes-of-prescribing-errors-ingeneral-practice. Accessed on 9 July 2019.

3. Claesson CB, Burman K, Nilsson JLG, Vinge E. Prescription errors detected by Swedish pharmacists. Int J Pharm Pract. 1995;3:151-6.

4. Khoja T, Neyaz Y, Qureshi NA, Magzoub MA, Haycox A, Walley T. Medication errors in primary care in Riyadh City, Saudi Arabia. East Mediterr Health J. 2011;17:156-9.

5. Gandhi TK, Weingart SN, Borus J. Adverse drug events in ambulatory care. New Engl J Med. 2003;348:1556-64.

6. Pham JC, Aswani MS, Rosen M, Lee H, Huddle M, Weeks K, et al. Reducing medical errors and adverse events. Annu Rev Med. 2012;63:447-63.

7. Dean B, Barber N, Schachter M. What is a prescribing error?. Qual Health Care. 2000;9:232-7.

8. Pote S, Tiwari P, D'Cruz S. Medication prescribing errors in a public teaching hospital in India: a prospective study. Pharm Pract. 2007;5(1):17-20.

9. Reddy LKV, Modi AG, Chaudhary B, Modi V, Patel M. Medication errors-a case study. J Acad Hosp Adm. 2009;21(1,2):28-34.
10. Karna K, Sharma S, Inamdar S, Bhandari A. Study and evaluation of medication errors in a tertiary care teaching hospital-a baseline study. Int J Pharm Sci. 2012;4(5):587-93.

11. Mohan P, Sharma AK, Panwar SS. Identification and quantification of prescription errors. Med J Armed Forces India. 2014;(70):149-53.

12. Neville RG, Robertson F, Livingstone S, Crombie IK. A classification of prescription errors. J R Coll Gen Pract. 1989;39(320):110-12.

13. How to investigate drug use in health facilities, selected drug use indicators. Available at http://www.apps.who.int/medicinedocs/pdf/s2289e.p df. Accessed on 9 July 2019.

14. Shanmugapriya S, Saravanam ST, Rajee SS, Venkatrajan R, Thomas PM. Drug prescription pattern of outpatients in a tertiary care teaching hospital in Tamil Nadu. Perspect Clin Res. 2018; 9(3):133-8.

15. Keny M, Rataboli PV. Look-alike and sound-alike drug brand names: a potential risk in clinical practice. Indian J Clin Pract. 2013;23(9):508-13.

16. Suman RK, Kumar R, Mohanty IR, Deshmukh YA. Assessment of drug usage pattern of antibiotics used in ENT OPD of tertiary care teaching hospital. Int $\mathbf{J}$ Health Sci Res. 2015;5(9):290-7.

17. Medication errors: technical series on safer primary care. Available at: https://apps.who.int/iris/bitstream/ handle/10665/252274/9789241511643-eng.pdf. Accessed on 9 March 2019.

18. Woodward MC, Streeton CL, Guttmann A, Killer GT, Peck RW. Polypharmacy management among Australian veterans: improving prescribing through the Australian department of veterans' affairs' prescriber feedback programme. Intern Med J. 2008;38(2):95-100.

19. Evidence scan: reducing prescribing errors April 2012. Available at: https://www.health.org.uk/sites/ default/files/ReducingPrescribingErrors.pdf. Accessed on 13 March 2019.

Cite this article as: Srinivasa J, Swamy S. Analysis of prescriptions for completeness in a tertiary care teaching hospital. Int J Basic Clin Pharmacol 2020;9:1849-53. 